\title{
Aproximación al modelo de ley que se configura en la Constitución de 1812
}

JosÉ F. CHOFRE SIRVENT

Si alguno de los modelos básicos para concebir la ley ha ejercido influencia sobre la Constitución de 1812 éste sería el basado en el principio parlamentario, también denominado «monismo legitimador excluyente del Parlamento», surgido con la Constitución francesa de 1791.

El modelo de ley «gaditano» tiene de común con el francés el que, en ambos, el poder legislativo ostenta la primacía por encima de los demás órganos del Estado, al configurarse aquél como el único representante de la nación soberana y, en consecuencia, como la fuente exclusiva de legitimidad. Sin embargo, entre uno y otro modelo existen diferencias tan sustanciales que vienen casi a ocultar la común característica respecto a la posición de las Cortes en la estructura constitucional.

Si la alta consideración que se atribuye a la ley en el «monismo parlamentario" lleva consigo la imposibilidad de establecer límite alguno a la voluntad del legislador, no es posible hacer igual afirmación respecto a la configuración de la ley en la Constitución de 1812. Esta Constitución no comulga en su integridad con las características que definen el modelo francés. Las diferencias entre los dos modelos de ley son tan relevantes que cabe referirse a la especial «originalidad» española en la definición de la ley.

Anteriormente hemos expresado que la superior posición que ocupa la ley en Francia conduce a que la voluntad del legislador no encuentre límite alguno en su producción normativa. En España, sin embargo, no es factible, en ningún caso, que la ley, o más propiamente, «decreto de Cortes con carácter de ley» ostente el valor de norma suprema 
del ordenamiento jurídico, porque su campo de acción está acotado por las materias reservadas a los «decretos de competencia exclusiva de las Cortes». La ley, por tanto, no lo puede todo, y lo que puede no es lo más importante (materias tan relevantes como pueden ser la reforma constitucional o las relativas a las contribuciones, entre otras muchas, no son objeto de «decreto de Cortes con carácter de ley», sino de «decreto de competencia exclusiva de las Cortes»).

Esta afirmación de que los «decretos de Cortes con carácter de ley» no pueden regular cualquier materia se deriva no sólo de una interpretación conjunta de la Constitución y de los dos Reglamentos de Cortes, de 1813 y 1821, sino también de un minucioso examen de la producción normativa elaborada por las Cortes durante el tiempo de vigencia de la Constitución de 1812. La evidencia resultante de estos análisis parece no haber sido captada plenamente por algunos importantes autores que han dedicado especial atención al estudio del sistema de fuentes. En este sentido destaca Javier Pérez Royo. ${ }^{1}$

Este autor señala que el punto de arranque del sistema de fuentes imperante en España desde el origen del Estado constitucional era la ley. «La ley era auténticamente soberana, era la única norma en el ordenamiento jurídico general, primaria y absolutamente incondicional». Si esta afirmación "podría» ser predicable respecto a Constituciones futuras - supuesto del que no estamos absolutamente seguros, por la creciente actividad del poder ejecutivo, en definitiva del Rey, y por el auge que va adquirir el «moderantismo» como presupuesto válido para justificar un cierto menoscabo de la ley-, no consideramos que pueda serlo con relación a la Constitución de 1812, porque en ésta el «decreto de Cortes con carácter de ley» no es sino una más de entre las diversas categorías normativas producidas por las Cortes. Concurriendo además la significativa circunstancia de que el «decreto de Cortes con carácter de ley» no es expresión directa y exclusiva de la soberanía nacional (Pérez Royo afirma que la «ley es auténticamente soberana»), ya que para su formación es precisa la voluntad del Rey y de las Cortes, mientras que, por el contrario, el «decreto de competencia exclusiva de las Cortes» sí expresa genuinamente la voluntad general de la nación representada en Cortes, al no exigirse el cumplimiento de la sanción de S.M. 
En definitiva, pues, la ley, o más exactamente, el «decreto de Cortes con carácter de ley», se configura como una categoría normativa que carece de la capacidad necesaria para regular cualquier campo de la actividad normativa, encontrándose sujeta a determinados límites impuestos por la propia Constitución. La ley, o «decreto de Cortes con carácter de ley», por tanto, «no lo puede todo» en la Constitución de 1812.

Llegados a este punto se hace necesario determinar las notas básicas que caracterizan al concepto de ley («decreto de Cortes con carácter de ley») propio de la burguesía.
A) El «decreto de Cortes con
carácter de ley» como expresión
de una concepción general de la
legalidad: ley y razón.

El imperio de la ley es un postulado común desde Aristóteles hasta Locke pasando por los pensadores medievales. Todos ellos consideran que la ley debe gobernar la organización política, aunque, obviamente, el mismo término alberga, según el momento histórico, contenidos distintos. Por lo que se refiere a la ley, el liberalismo introdujo dos cambios de significativa relevancia. Por una parte, la ley positiva no tiene que ser conforme con la ley divina; la ley positiva obliga a la totalidad de los individuos, pero la razón de esta obligatoriedad deriva de su congruencia con la ley natural racional. Y, por otra parte, el liberalismo introdujo una concreta forma de ley. El concepto de ley que dimana ya no es un simple mandato del Rey absoluto y soberano, sino que al configurarse las Cortes como único órgano soberano que representa a la nación, la ley deviene como «expresión de la voluntad general», como indicábamos anteriormente.

La ley en el liberalismo representa la posibilidad de planificar y racionalizar la vida y el poder político con vocación de futuro y permanencia. En este contexto la ley lo puede todo - en el marco de la Constitución de 1812 es preciso matizar esta afirmación teniendo en cuenta el relevante papel que desempeñan los «decretos de competencia exclusiva de las Cortes»-, y, además, el órgano legislativo del cual emanan, 
Parlamentos o Cortes, disfrutan de una capacidad de transformación casi ilimitada, de ahí que sea expresión muy aceptada hablar de «absolutismo parlamentario».

La ley, por tanto, se configura como un producto exclusivo de la razón humana. Adolfo Posada, al referirse a la Constitución de 1812, señala que, al recoger ésta en un todo ordenado las normas políticas fundamentales, puede reputarse como una obra reflexiva del legislador constituyente, y que es, a su vez, una «manifestación de la fe en la ley y en la eficacia de la acción creadora de la razón». ${ }^{2}$ Se producía una equiparación entre ley y razón, propia de la Ilustración. Fe en la ley como fe en razón, y viceversa. El racionalismo, pues, se manifiesta extensamente en estos años iniciales del constitucionalismo español. Así, y como muestras representativas, señalemos dos intervenciones parlamentarias que inciden en este aspecto. Por una parte, el diputado señor Ostolaza, siguiendo con la discusión del artículo 12, Capítulo II, del Reglamento del Poder Ejecutivo, afirma que la ley «debe estar fundada en la razón»; ; y, por otra parte, el diputado señor Riesco, durante la discusión sobre la primera proposición de los señores americanos acerca de la igualdad de la representación de las Américas, afirma «que los americanos, apoyados en la recta razón, que es la verdadera ley».4

De todas las fuentes del Derecho sólo la ley permite abordar cambios revolucionarios, pero una vez que la burguesía ha logrado destruir las posiciones de los sè̃ores feudales y del absolutismo monárquico, construye su propio sistema jurídico-normativo haciendo desaparecer sus genuinas implicaciones revolucionarias que identificaban «lex»y «ratio» (aunque en el contexto de la Constitución de 1812, seguramente, tienen mayor capacidad revolucionaria el «decreto de competencia exclusiva de las Cortes», porque representa más genuinamente la voluntad de la nación española al no exigirse en los mismos la intervención del Rey por medio de la sanción). Pero inicialmente «el racionalismo acude al uso, y aun al abuso, de la legislación en su ímpetu de reformar velozmente la obra lenta de la Historia». ${ }^{5}$ La obra legislativa de las Cortes de Cádiz parece acusar este excesivo racionalismo - de clara influencia francesa- que conducía a la aprobación de leyes o «decretos de Cortes con carácter de ley» $\mathrm{y}$ «decretos de competencia exclusiva de 
las Cortes» que no respondían a los intereses de la sociedad por ser excesivamente artificiales en su elaboración. Es una circunstancia reconocida por diversos autores el "divorcio» existente entre las Cortes y el eje activo de la vida del país. ${ }^{6}$ En este mismo sentido se pronuncia Díez del Corral cuando señala que, mientras España se desangra, los legisladores gaditanos se disponen a acometer una «utópica tarea legislativa» a espaldas de la realidad social. ${ }^{7}$

Como conclusión, y siguiendo a García Pelayo, «la noción de legalidad jurídica se inserta en una concepción general de la legalidad cuyos supuestos son la universalidad de la razón, la identidad de la naturaleza humana y la fuerza estructuradora del supuesto». ${ }^{8}$ En este contexto, influido por un subyacente racionalismo iusnaturalista, debemos ubicar el «decreto de Cortes con carácter de ley» y el «decreto de competencia exclusiva de las Cortes» producidos en el marco de la Constitución de 1812. El análisis que se acomete de estas dos categorías normativas no puede ser ajeno en modo alguno a este condicionamiento histórico-ideológico.

B) El «decreto de Cortes con carácter de ley» como expresión de la voluntad general: consideraciones críticas

desde la perspectiva de la Constitución de 1812.

La consideración de la ley como «expresión de la voluntad general», como ya se estableció en el art. $6 .^{\circ}$ de la Declaración de los Derechos del Hombre y del ciudadano, de 26 de agosto de 1789, constituye una clara manifestación de la ruptura con respecto al Antiguo Régimen. En éste la ley no era sino la expresión de la voluntad del monarca. En el constitucionalismo, por el contrario, las leyes son expresión de la voluntad de los representantes de la nación, y una vez aprobadas y promulgadas, adquieren autonomía propia, desligándose de cualquier atadura personal. ${ }^{9}$

No obstante, en los orígenes del constitucionalismo español se manifestaron en el orden teórico y doctrinal dos diferentes concepciones de la ley. Una, representante del pensamiento liberal, y que identifica 
a la ley con la expresión de la vołuntad general («llámese ley la expresión de la voluntad de los socios manifestada por ellos»); ${ }^{10} \mathrm{y}$ otra, todavía basada en la concepción tomista, y que define la ley como «una ordenanza o mandato racional dirigido al bien común y promulgado por el que tiene a su cargo el Gobierno de la sociedad».

La discrepancia entre ambas concepciones acerca de la ley se manifestaría en los términos siguientes: «No explican (los defensores liberales) si esta voluntad ha de ser justa o injusta, racional o irracional, sin duda porque, como afirma uno de los nuevos maestros, bueno o malo, virtud o vicio $\mathrm{y}$, de consiguiente, justo o injusto, depende de la opinión y en el mismo hecho de ser la voluntad general tiene a su favor la opinión y esto basta para ser racional y justicia». ${ }^{11}$ De las evidentes divergencias entre ambas concepciones de la ley se deriva que, por una parte, para los partidarios del absolutismo la adecuación de la ley positiva con la ley natural corresponde establecerla exclusivamente a quien detente el poder absoluto; mientras que, por el contrario, para los liberales la correspondiencia entre ley positiva y ley natural es consecuencia de la suma de voluntades expresadas en el seno de las Cortes, que es la unión de todos los diputados que representan la nación. Por tanto, una ley será buena o justa con tal que reúna la mayoría de sufragios, sin necesidad de atender a ninguna instancia superior.

El choque producido entre ambas concepciones llevó a algunos autores a armonizar una y otra idea en un tercer concepto de ley. Así, José Caro y Sureda, en su obra Catecismo político, llegó a definir la ley como «la expresión de la voluntad general en orden a lo que conviene mandar o prohibir para el bien de todos». ${ }^{12}$

Pero, finalmente, la concepción de la ley que adquirió carta de naturaleza era la que encontraba sus fundamentos en el liberalismo: no cabe referirse a la idea de ley si ésta no representa la voluntad de la Nación.

Por tanto, el valor de las leyes hechas con el acuerdo de las Cortes no es el mismo que el de aquéllas que son el resultado de la voluntad del Rey. El diputado señor Calatrava no llamaría a éstas «leyes», sino ordenanzas o decretos interinos reservándose la utilización del término 
«ley» para cuando se manifieste la voluntad de las Cortes, expresión del interés de los pueblos y de la Nación, «que es lo que da el carácter de ley». ${ }^{13}$ En definitiva, se considera al «decreto de Cortes con carácter de ley» como un acto de soberanía.

Pero la conceptuación del «decreto de Cortes con carácter de ley» como expresión de la voluntad general de la Nación expresada en las Cortes, sin dejar de ser válida, exige que la precisemos para poder ajustarla a sus propios términos y al contexto histórico de la época.

Así, en primer lugar, conviene advertir que, afirmar en 1820 (no aludimos al período 1810-1814 porque no se aprobaron «decretos de Cortes con carácter de ley») que la «ley es la expresión de la voluntad general» no es más que una cuestión de principio, porque bien sabido es la escasísima participación del pueblo en la elección de los diputados. ${ }^{14}$ En todo caso sería la expresión de la voluntad general de una determinada clase social, pero no de todo el pueblo, como parece indicar la definición anterior de la ley.

$\mathrm{Y}$, en segundo lugar, y siguiendo al diputado señor Martínez de la Rosa, «no es exacto que la ley sea la expresión de la voluntad general», y no lo es porque si toda expresión de la voluntad general fuera ley, todo lo que las Cortes mandasen sería ley, es así que las Cortes además de leyes aprueban otros tipos normativos como, por ejemplo, «decretos de Cortes» $\mathrm{y}$ «Órdenes», luego, por tanto, la voluntad general no se expresa exclusivamente por ley, sino también a través de otras categorías normativas. ${ }^{15}$ Fundamentalmente, este segundo argumento invocado como corrección a la consideración de la ley como «expresión de la voluntad general» es totalmente coherente con la línea argumental seguida hasta ahora en virtud de la cual el «decreto de Cortes con carácter de ley» es una más de entre las diferentes categorías normativas producidas por las Cortes, $\mathrm{y}$, si cabe, ni siquiera es la más importante. En otras palabras, el «decreto de Cortes con carácter de ley» expresa la voluntad general de la Nación, pero también realizan esta función los demás «decretos de Cortes». Y es más, la voluntad general de la nación queda más genuinamente expresada por los «decretos de competencia exclusiva de las Cortes», que por las propias leyes o «decretos de Cortes con carácter de ley», ya que éstas precisan la intervención del 
Rey por medio de la sanción, pudiendo ejercer el veto suspensivo, bloqueándose temporalmente de este modo la voluntad de la nación representada en las Cortes.

C) Generalidad de los «decretos de Cortes con carácter de ley» y de los «decretos de competencia exclusiva de las Cortes».

En los comienzos del constitucionalismo el concepto de ley y ley general eran sinónimos. La generalidad era una condición sustancial al concepto de ley. La ausencia de aquélla suponía la inexistencia misma del concepto de ley.

Así, pues, una de las características más tradicionales y fundamentales del concepto de «ley» («decreto de Cortes con carácter de ley») es la «generalidad», entendida en el sentido de que la regulación que se contenga en la ley no debe circunscribirse a unos concretos y determinados casos, sino a todos aquellos indefinidos supuestos que puedan surgir en tanto dicha ley se encuentra en vigor. ${ }^{16}$ Anteriormente señalábamos que la voluntad general se expresa tanto por «decreto de Cortes con carácter de ley» como por los demás «decretos de Cortes», pero cualquiera que sea una de las dos categorías, ¿ha de cumplir el requisito de la generalidad?

a) La generalidad y los «decretos de Cortes con carácter de ley».

Esta misma idea de generalidad propia de la burguesía se encuentra sostenida por los diputados de Cádiz. Así, el Diputado señor Moreno Guerra, en la discusión sobre el plan de Hacienda, en particular sobre «regalías de aposentos», afirmaba que «las leyes deben ser generales, y no reparar en pequeños accidentes, ni hacer excepciones ridículas y odiosas»» ${ }^{17}$ En igual sentido se manifiesta el diputado señor Cortés en una intervención parlamentaria cuando afirma que: «Estas (las Cortes) como cuerpo legislativo, no deben ocuparse en casos particulares: sus leyes y determinaciones deben ser siempre uniformes y generales». ${ }^{18} \mathrm{Y}$ de idéntico parecer es la opinión del diputado señor Romero que, con ocasión de la discusión del proyecto de gobierno económico-político de 
las provincias, afirma que: «El carácter de la ley es proveer a los casos generales; pero un caso particular no puede ser objeto de ley. ${ }^{19}$

Por tanto, según la opinión común de los diputados, el requisito de la «generalidad» es inherente al concepto de ley o «decreto de Cortes con carácter de ley» derivado de la Constitución de 1812.

La «generalidad», además, se encuentra estrechamente vinculada, según algunos diputados, a valores de justicia ${ }^{20} \mathrm{Si}$ una determinada ley carece de la condición esencial de la "generalidad» no sería «justa», porque respondería a la idea de parcialidad. Ante los grandes conflictos de intereses que han de enfrentarse las Cortes cuando elaboren una ley, el único «consuelo» de que disfrutan los ciudadanos es el de la «universalidad de la ley», "porque nada hay que conturbe e incomode más al hombre que la idea de parcialidad e injusticia». ${ }^{21}$

b) La generalidad y los «decretos

de competencia exclusiva de las

Cortes».

Si bien ha quedado suficientemente aclarado que la "generalidad» es una condición esencial del concepto de «ley» o «decreto de Cortes con carácter de ley», sin la cual ésta no puede existir (corresponderá contrastar esta opinión con la práctica parlamentaria desarrollada durante los años de vigencia de la Constitución de 1812), no cabría realizar igual afirmación cuando se trate de «decretos de competencia exclusiva de las Cortes». Que la «universalidad» es una «obligación general que debe distinguir a las leyes» de otras categorías normativas ya se contenía en el dictamen de la Comisión que ha entendido de la reforma del decreto sobre rehabilitación de empleados. ${ }^{22}$ Es así, pues, que en los «decretos de competencia exclusiva de las Cortes» el requisito de la "generalidad» no es de inexcusable cumplimiento. Precisamente, estos decretos están pensados para aquéllos supuestos particulares de cuya regulación queda excluido el «decreto de Cortes con carácter de ley» (piénsese en todas las materias comprendidas entre los apartados $2 .^{\circ}$ y $26 .^{\circ}$ del artículo 131 de la Constitución).

La distinción entre "decreto de Cortes con carácter de ley» y «decreto de competencia exclusiva de las Cortes», en referencia al concreto 
aspecto de la «generalidad», ha sido seguida, implícitamente, por la mayoría de los diputados, como ya hemos tenido ocasión de señalar. Pero, sin embargo, existe un parlamentario que parece haber profundizado más en este sentido. Concretamente nos referimos al diputado señor Martínez de la Rosa, en cuya intervención en las Cortes define los tres requisitos que forman los «decretos de Cortes con carácter de ley «: «El carácter del asunto, su generalidad y permanencia». ${ }^{23}$ «el carácter del asunto» lleva en sí mismo una carga adicional de indefinición que dificulta su interpretación, pero, en cualquier caso, este requisito definidor del «decreto de Cortes con carácter ley», para diferenciarla del «decreto de competencia exclusiva de las Cortes», ya se contenía, incluso, en el «Reglamento para el Gobierno interior de las Cortes», de 24 de noviembre de 1810, en el que se hablaba de "naturaleza del asunto» (art. 2, del Capítulo VI), o «asuntos que se gradúen según su importancia» (art. 13, del Capítulo VI). Pues bien, la vinculación de la «generalidad» -además de la "permanencia»- al «carácter del asunto» viene a corroborar la sustancialidad de la misma en la definición del concepto de ley ("decreto de Cortes con carácter de ley») y no en la de «decreto de Cortes sin carácter de ley».

\section{D) Ley e igualdad.}

El reconocimiento de la igualdad, como uno de los principios que debe contener toda ley está presente en Cádiz. Así, en una intervención ante las Cortes, el diputado señor Calderón manifestaba que los principios fundamentales que debe contener toda ley son la libertad y la igualdad. ${ }^{24}$ Carlos de Cabo señala, como una de las exigencias derivadas de la imposición revolucionaria del modo de producción capitalista, «la vigencia plena de los principios de libertad e igualdad necesarios para el desarrollo de las nuevas relaciones de producción». ${ }^{25}$ Estos principios, fundamentales para el desarrollo de capitalismo, son a la misma vez esenciales para el concepto de ley. De tal manera, que el concepto de ley que se configure responde a los intereses del nuevo modo de producción.

Desde una perspectiva distinta Carl Schmitt viene a recordar que el Estado burgués de Derecho se basa en la libertad y en la igualdad de 
los ciudadanos, y que tanto un principio como el otro presuponen el concepto de ley que dicho autor señala como propio del Estado de derecho $^{26}$ y que tiene como premisa necesaria el requisito de la generalidad. No sería admisible, pues, proclamar la existencia del principio de igualdad si antes no se ha hecho un expreso reconocimiento de la generalidad.

En todo caso, el reconocimiento de la «igualdad» supuso una ruptura radical, al menos desde una perspectiva formal, con respecto al Antiguo Régimen. En el Derecho estamental los súbditos no eran iguales ante la ley debido a la existencia de privilegios individuales y estamentales. La eliminación de estos privilegios para alcanzar un tipo de sociedad formada por hombres iguales jurídicamente fue uno de los objetivos que se propuso la burguesía. Aunque, en verdad, no puede desconocerse que la conquista de la igualdad fue más aparente que real. No olvidemos que la burguesía luchó contra los privilegios estamentales del Antiguo Régimen con el objetivo de alcanzar la igualdad ante la ley; sin embargo, es conocido, que una vez conquistado dicho objetivo con la consiguiente caída del Antiguo Régimen, no demostró la misma predisposición para mantener la igualdad entre ella y las clases populares. Es por ello que la igualdad no fue real, sino formal.

En el Discurso Preliminar a la Constitución de 1812 se manifestaba con especial énfasis que las leyes positivas «no pueden conocer diferencia ninguna de condiciones ni de clases entre los individuos de este mismo Estado. La ley ha de ser una para todos». ${ }^{27}$ Se aprecia con nitidez que la igualdad constituye una condición sustancial a la ley. No puede admitirse la existencia de un concepto de ley que desconozca este principio básico. Bajo el «suave yugo de la ley... todos aparecen iguales». ${ }^{28}$

Este principio de igualdad legal de los españoles ${ }^{29}$ exige, como consecuencia derivada del mismo, el reconocimiento de la «unidad de fuero», ${ }^{30} \mathrm{y}$ «que el código universal de leyes positivas sea uno mismo para toda la nación». ${ }^{31}$ Nación que se encuentra formada por hombres iguales entre sí, respondiendo al concepto surgido con la Revolución francesa, que la configura como un todo homogéneo y único. 
El empeño puesto por la burguesía en la conquista de la igualdad de derechos de todos los españoles tenía un alcance mayor del que aparentemente pudiera pensarse. Le subyacía el interés por establecer la unidad del ordenamiento jurídico con el fin de evitar situaciones de privilegio que no se correspondían y podrían chocar con la estructura políticoconstitucional del nuevo régimen.

Por todo ello, se consagró el principio de igualdad de todos los ciudadanos ante la ley hasta el punto de considerarse como uno de los «dogmas del símbolo social». ${ }^{32}$ No obstante, Ramón Salas pone de manifiesto el frustrado deseo de ver plasmado expresamente en el texto constitucional dicho principio. ${ }^{33}$

Además de las referencias al principio de igualdad contenidas en el Discurso Preliminar, una de las primeras manifestaciones que incidieron expresamente en el referido principio corrió a cargo del diputado señor Argüelles, en 12 de septiembre de 1811, con motivo de la aprobación del Decreto sobre abolición de los señoríos, en los siguientes y escuetos términos: «Después del decreto de señoríos, las leyes ya no pueden menos de ser iguales para todos los españoles». ${ }^{34}$ También se invocó la igualdad con ocasión de dar cuenta de una representación de don Gregorio Antonio Fitzgerard, en 5 de septiembre de 1812, y en ella se exponía «que delante de la ley lo mismo es el Regente que el más pobre de los españoles». ${ }^{35}$

Ya en el «trienio liberal» se volvió a incidir en este aspecto tan sustancial del concepto de ley como es el de la igualdad. En este sentido se pronuncia el diputado señor Martínez de la Rosa cuando afirma que: «Delante de la ley todos los ciudadanos son iguales; diré más; no hay ninguno que sea pequeño», ${ }^{36} \mathrm{y}$ también con ocasión de la discusión del dictamen de la Comisión ordinaria de Hacienda sobre puertos públicos, el diputado señor Moreno Guerra recordó un principio ya conocido y referido en otros momentos: «en España, después de la Constitución, la ley ha de ser igual para todos, y sin privilegio». ${ }^{37}$

En definitiva, el «decreto de Cortes con carácter de ley» es uno mismo para todos, no existiendo aquellos odiosos privilegios que correspondían a tiempos pasados. La igualdad se configura, pues, como un elemento esencial del concepto de ley propio de la burguesía. 


\section{NOT A S :}

1. En este mismo sentido se manifiesta Pérez Royo, Javier, Las fuentes del Derecho, Madrid, 1984, pág. 16.

2. Vid. Posada, Adolfo, Tratado de Derecho Político, Tomo II, Madrid, 1935, pág. 275. Pacheco, Joaquín Francisco, señala igualmente que «la ley no es un acto de voluntad, sino un acto de razón", vid. Lecciones de Derecho Político, Madrid, 1984, pág. 57. Aunque en otro contexto, también Alcalá Galiano se refiere a que los pueblos «miren con fe a las leyes», vid Lecciones de Derecho Político, Madrid, 1984, pág. 298.

3. Vid. Diario de Sesiones de las Cortes Generales y Extraordinarias, Tomo I, núm. 91, 23 de diciembre de 1810, pág. 233.

4. Vid. Diario de Sesiones de las Cortes Generales y Extraordinarias, Tomo I, núm. 112, 16 de enero de 1811 , págs. 377 y 378.

5. Vid. Pérez Serrano, Nicolás, «Constitucionalismo y codificación», en Estudios de Derecho Político, Tomo II, Madrid, 1984, pág. 722.

6. Vid. Jutglar, Antoni, Ideologías y clases en la España contemporánea (1808-1874), Madrid, 1973, pág. 39.

7. Vid. Díez del Corral, Luis, El Liberalismo doctrinario, Madrid, 1973, pág. 489.

8. Vid. García Pelayo, Manuel, Derecho Constitucional comparado, Madrid, 1959, págs. 63 y ss.

9. En esta misma línea afirma Martínez de la Rosa que: «yo no quiero que la libertad individual de los españoles dependa de las personas, sino de las leyes», vid. Diario de Sesiones de las Cortes, Legislatura Extraordinaria, 1821-1822, núm. 130, 2 de febrero de 1822, pág. 2.122 .

10. Vid. Reflexiones sociales, Valencia, 1811, cit. por Artola, Miguel, en Los orígenes de la España contemporánea, Tomo I, Madrid, 1975, pág. 655.

11. Vid. El Procurador general, núm. 90, 29 de diciembre de 1812, cit. por Artola, Miguel, en op. cit., pág. 655 .

12. Vid. Catecismo político, arreglado a la Constitución de la monarquía española. Para ilustración del pueblo, instrucción de la juventud y uso de las escuelas de primeras letras, Cádiz, 1812, cit., por Artola, Miguel, en op. cit., pág. 656.

13. Vid. Diario de Sesiones de las Cortes, 1821, Tomo II, núm. 55, 23 de abril de 1821, pág. 1.238 .

14. Los requisitos que señala la Constitución de 1812 para ser elegido diputado son los siguientes: primero, ciudadano en el ejercicio de sus derechos (art. 91); segundo, mayor de veinticinco años (art. 91); tercero, que haya nacido en la provincia, o esté avecindado en ella con residencia a lo menos de siete años, bien sea del estado seglar, o del eclesiástico secular; pudiendo recaer la elección en los ciudadanos que componen la junta, o en los de fuera de 
ella (art. 91); cuarto, renta anual proporcionada, procedente de bienes propios (art. 92). Este último requisito queda en supenso hasta que las Cortes, que han de celebrarse, señalen la cuota de renta y la calidad de los bienes de que haya de provenir (art. 93).

15. Vid. la intervención del diputado señor Martínez de la Rosa, que se expresó en los siguientes términos: «Me he levantado sólo para impugnar el que sea ley este reglamento (se refiere al reglamento de las Cortes). En ciertas materias pueden estar tan confundidos los límites que sea difícil distinguir la ley del decreto; pero tratándose del reglamento del gobierno interior de un cuerpo, no puede dudarse que no es ley. No es exacto que la ley sea la expresión de la voluntad general; y aunque así lo han dicho autores célebres, no lo tengo por un principio infalible. Si toda expresión de la voluntad general fuese ley, todo lo que las Cortes mandasen sería ley; es así que no lo es, luego es clara la consecuencia». Diario de Sesiones de las Cortes, Tomo I, núm. 57, 29 de agosto de 1820, pág. 725 .

16. Vid. García Pelayo, Manuel, en op. cit., págs. 68 y 69. Algunos autores como, por ejemplo, Laband, G. Jellinek o Anschütz, estiman que la «universalidad» no constituye elemento esencial del concepto de ley, pues pueden plantearse situaciones en las que no sea posible resolverlas invocando normas de carácter general, siendo por ello necesario normas individuales o particulares. Vid. Starck, Christian, El concepto de ley en la Constitución alemana, Madrid, 1979, pág. 138. Ciertamente, la generalidad no supone universalidad, sino que en el ámbito de un determinado círculo de personas o relaciones sean comprendidos todos los casos. Hay otros autores que estiman que la «generalidad» de la ley no se refiere a su objeto ni a la indeterminación del número de actos a regular, sino que afecta a su finalidad y eficacia general. Así, Federico de Castro, siguiendo a Suárez en el tema de los privilegios, afirmará que la ley, normalmente será general, pero no precisa tener un objeto general o determinado de manera abstracta («lex generalis»), sino que puede tener uno individualmente concretado («lex specialis»). Vid. Castro, Federico de, Derecho civil de España, Madrid, 1984, pág. 355. El supuesto básico para que el Estado de Derecho pueda adquirir pleno desarrollo se encuentra precisamente en el «carácter general de una norma jurídica». Como decía Gneist, esta exigencia constituye el «punto de Arquídemes del Estado de Derecho, cit. por Carl Schmitt, en Teoría de la Constitución, Madrid, 1982, pág. 159.

17. Vid. Diario de Sesiones de las Cortes, Tomo II, núm. 97, 9 de octubre de 1820, pág. 1.517.

18. Vid. Diario de Sesiones de las Cortes, Tomo I, núm. 18, 15 de marzo de 1821, pág. 482.

19. Vid. Diario de Sesiones de las Cortes, Tomo II, núm. 111, 26 de mayo de 1822, pág. 1.573.

20. Afirma el diputado señor Calatrava ante las Cortes que: «Las leyes deben ser generales, y si no, no son leyes, o por lo menos no son justas». Vid. Diario de Sesiones de las Cortes, Tomo I, núm. 55, 28 de agosto de 1820, pág. 696; en el mismo sentido que el diputado señor Calatrava se pronuncia el diputado señor La-Santa, en Diario de Sesiones de las Cortes, Tomo I, núm. 77, 13 de septiembre de 1820, pág. 982. Coincide esta opinión con la que después expresará Carl Schmitt cuando afirma «que la Ley en el sentido del Estado de Derecho significa una regulación normativa, dominada por la idea de Justicia», vid. de este autor Teoría de la Constitución, Madrid, 1982, pág. 162. Vid. la intervención del diputado señor La-Santa Diario de Sesiones de las Cortes, Tomo II, núm. 71, 13 de septiembre de 1820, pág. 982 . 
22. En el dictamen de la Comisión que ha entendido de la reforma del decreto sobre rehabilitación de empleados se dice lo siguiente: «¿Ni cómo las Cortes pudieron haber dado el carácter de ley a unos decretos que en su objeto no comprenden aquella universidad, aquella obligación general que debe distinguir a las leyes? Si tal hubiera hecho, no estarian en la resolución muy de acuerdo con los principios sancionados en la Constitución». Vid. Actas de las Sesiones de Cortes, Legislatura ordinaria, Tomo único, núm. 60, 19 de abril de 1814, pág. 276.

23. Vid. Diario de Sesiones de las Cortes, Tomo I, núm. 57, 29 de agosto de 1820, pág. 725.

24. Vid. Diario de Sesiones de las Cortes, Legislatura Extraordinaria, 1821-1822, Tomo II, núm. 58, pág. 895 .

25. Vid. Cabo, Carlos de, Sobre la función histórica del constitucionalismo y sus posibles transformaciones, Universidad de Salamanca, 1978, pág. 5.

26. Vid. de este autor la op. cit., pág. 161.

27. Vid. Argüelles, Agustín de, Discurso Preliminar a la Constitución de 1812, Madrid, 1981, pág. 95 .

28. «De todas las instituciones humanas, ninguna es más sublime ni más digna de admiración que la que limita en los hombres la libertad natural, sujetándolos al suave yugo de la ley. A su vista todos aparecen iguales, y la imparcialidad con que se observen las reglas que prescribe será siempre el verdadero criterio para conocer si hay o no libertad civil en un Estado». Vid. ídem. pág. 95.

29. Vid. ídem., pág. 104.

30. Vid. idem., pág. 100.

31. Vid. ídem., págs. 101 y 102.

32. Vid. Salas, Ramón, Lecciones de Derecho Público Constitucional, Madrid, 1982, págs. 45 a 47.

33. Vid. Bermejo Vera, José Luis, en el Estudio Preliminar a la obra de Salas, Ramón, Lecciones de Derecho Público Constitucional, Madrid, 1982, pág. XLIII.

34. Vid. Diario de Sesiones de las Cortes Generales y Extraordinarias, Tomo III, núm. 345, 12 de septiembre de 1811 , pág. 1.830 .

35. Vid. Diario de Sesiones de las Cortes Generales y Extraordinarias, Tomo V, núm. 655, 12 de septiembre de 1812, pág. 3.683. Aunque en otro contexto diferente al constitucional, el requisito de la igualdad se encuentra también vinculado a la ley. Así, el señor Valls expresa la siguiente opinión: «Las leyes son el compendio de la voluntad del monarca... La igualdad es el distintivo de la justicia y sería la mayor impropiedad el pretender que una misma voluntad se mueva por razones distintas y aún encontradas. Así que la razón exige que la voluntad del Rey sea igual para todos sus vasallos, y, por lo mismo, que todos se gobiernen por unas mismas leyes». Vid. Valls, 24 de septiembre de 1809, A.C. leg. 6, núm. 29, cit. por Artola, Miguel, Los origenes de la España contemporánea, Tomo I, Madrid, 1975, pág. 359. 
36. Vid. Diario de Sesiones de las Cortes, Tomo I, núm. 63, 5 de septiembre de 1820, pág. 828 .

37. Vid. Diario de Sesiones de las Cortes, Tomo III, núm. 115, 27 de octubre de 1820, pág. 1.924. 